\title{
Malnutrition is an independent factor associated with nosocomial infections
}

\author{
Stéphane M. Schneider ${ }^{1 *}$, Patricia Veyres ${ }^{2}$, Xavier Pivot $^{3}$, Anne-Marie Soummer ${ }^{4}$, Patrick Jambou ${ }^{2}$, \\ Jérôme Filippi ${ }^{1}$, Emmanuel van Obberghen ${ }^{4}$ and Xavier Hébuterne ${ }^{1}$ \\ ${ }^{1}$ Comité de Liaison Alimentation-Nutrition, CHU de Nice, France \\ ${ }^{2}$ Comité de Lutte contre l'Infection Nosocomiale, CHU de Nice, France \\ ${ }^{3}$ Service d'Oncologie, $\mathrm{CHU}$ de Besançon, France \\ ${ }^{4}$ Laboratoire de Biochimie, $\mathrm{CHU}$ de Nice, France
}

\begin{abstract}
The aim of the present prospective study was to determine if malnutrition, measured using a simple validated score, is an independent risk factor for nosocomial infections (NI) in non-selected hospital in-patients. Between 29 and 31 May 2001, a survey on the prevalence of NI was conducted on all 1637 in-patients (61 (SD 25) years old) in a French university hospital as part of a national survey. Actual and usual body weights were recorded in all in-patients, and serum albumin levels were measured on all blood samples taken during the week before the study. Nutritional status was evaluated by using the nutritional risk index (NRI). Albumin values were obtained in 1084 patients, and complete weight information was obtained in 911. Therefore, NRI was calculated in 630 patients (61 (SD 20) years old): 427 (67.8\%) were malnourished. NI prevalence was $8.7 \%: 4.4 \%$ in non-malnourished patients, $7.6 \%$ in moderately malnourished patients and $14.6 \%$ in severely malnourished patients. In univariate analysis, the odds ratios for NI were 1.46 (95\% CI 1.2, 2.1) in moderately malnourished patients and 4.98 (95\% CI 4.6, 6.4) in severely malnourished patients. In multivariate analysis, age, immunodeficiency and NRI class influenced NI risk. Vascular and urinary catheters, and surgical intervention, were the extrinsic factors associated with NI, with odds ratios ranging from $2.0(95 \%$ CI $1.8,2.6)$ for vascular catheters to $10.8(95 \%$ CI 8.8, 12.6) for association of the three factors. In conclusion, in non-selected hospitalized patients, malnutrition assessed with a simple and objective marker is an independent risk factor for NI. An early screening for malnutrition may therefore be helpful to reduce the high prevalence of NI.
\end{abstract}

Nosocomial infections: Protein-energy malnutrition: Hospitals: Surgical wound infection: Urinary catheterization: Immunocompromised host

There are approximately 2 million nosocomial infections (NI) per year in the USA, and 600000 per year in France (Jarvis, 1996; Anonymous, 2000). Patients who develop NI are two to three times as likely to die, $60 \%$ more likely to spend time in an intensive care unit, and two to five times more likely to be readmitted to hospital (Kirkland et al. 1999) than those who do not. It as been estimated that $1 \%$ of all patients with an NI die as a direct result of the infection, and that NI contribute to the death of $2.7 \%$ of all patients admitted to hospital (Anonymous, 1992). Thus, NI could be responsible for $6-10 \%$ of all intra-hospital deaths (Garcia-Martin et al. 2001). The excess duration of hospitalization secondary to NI ranges from $1-4 \mathrm{~d}$ for urinary tract infections to 6.8-30.0 d for pneumonia (Jarvis, 1996).

NI represent a direct economic liability of US\$5-10 billion per year in the USA and US\$760 million per year in Europe (Wenzel, 1985; Worming, 1994). The estimated extra direct costs per infection range from US\$558-593 for each urinary tract infection to US\$4947 for each case of pneumonia. In countries with prospective payment systems based on diagnosis-related groups, hospitals lose from US\$583 to US\$4886 for each NI (Jarvis, 1996). Programmes that reduce the incidence of NI can substantially decrease morbidity and mortality and reduce the economic burden for patients and hospitals.

For the last 20 years, health professionals have been alerted to a high prevalence of malnutrition among hospitalized patients ranging between 20 and $60 \%$ (McWhirter \& Pennington, 1994; Naber et al. 1997b). Malnutrition is independently responsible for an increased rate of hospital morbidity including infections, pressure ulcers and delays in wound healing (Naber et al. 1997a,b); all these conditions can result in an increased length of stay and mortality (Robinson et al. 1987; Anker et al. 1997; McClave et al. 1992; Galanos et al. 1997). Nutrition and infection interact through different pathways, the most important being an impairment of non-specific and cell-mediated immunity (Scrimshaw \& SanGiovanni, 1997). Several studies have reported infections (most of them supposedly NI) as a complication of malnutrition in selected populations (McClave et al. 1992; Rady et al. 1997; Llop 
et al. 2001). However, in these studies fulfilment of NI definitions was not mentioned or assessed, and it is impossible to confirm whether these infections were acquired in the hospital setting; therefore, until now, whether malnutrition is an independent factor associated with NI in non-selected hospital in-patients remains unknown. The aim of this prospective study was, therefore, to assess the influence of malnutrition on the prevalence of NI in non-selected hospital in-patients.

\section{Subjects and methods}

Between 21 May and 23 June 2001, a nationwide survey of the prevalence of NI was conducted in every hospital ward in France that agreed to participate when asked by the local Committee Against Nosocomial Infections (Comité de Lutte contre les Infections Nosocomiales). Every type of ward (acute-care, intermediate-care, long-stay) was included, except for day- or night-care and outpatient clinics. The prevalence of active NI (excluding those whose treatment had been completed by the time of the study) was determined by a team of trained hospital investigators who visited each hospitalized patient and reviewed his/her medical records with a referring physician and nurse from each ward. Medical history reviewed included immunodeficiency (HIV infection with CD4 cells $<0.5 \mathrm{G} / 1$, cancer with metastasis, haemopathy, immunosuppressive treatment including steroids, chemotherapy and radiation therapy), surgery, presence of a vascular or urinary catheter, and anti-infectious treatment. NI was defined as a well-documented infection absent on admission, and surgical-site infection was defined as an infection occurring in the $30 \mathrm{~d}$ following surgery (1 year for an implant or a prosthesis); the Centers for Disease Control and Prevention's definitions of NI were fulfilled in each case (Garner et al. 1988; Horan et al. 1992). In order to detect NI, investigators relied on the patient's records (high temperature, antibiotic prescription, bacteriology tests ordered), and interviewed patients, physicians and nurses. Only those NI with clinical and/or biological confirmation were considered. A $48-72 \mathrm{~h}$ follow-up was sometimes necessary to confirm or refute the diagnosis. Systematic screening for urinary tract infection (Multistix 9 SG reagent strip; Bayer Diagnostics, Puteaux, France) was performed in all patients who had a urinary catheter in place the day of the survey or during any of the previous $7 \mathrm{~d}$; a urine culture was performed if the strip was positive, and the strip alone was not used in the diagnosis of NI.

The University Hospital of Nice is a referral hospital in south-east France. In this hospital, the Food and Nutrition Liaison Committee (Comité de Liaison AlimentationNutrition) and the Comité de Lutte contre les Infections Nosocomiales decided to add a nutritional survey to the NI prevalence survey (which was conducted over $2 \mathrm{~d}$ ), with the systematic determination of the nutrition risk index (NRI) in all in-patients. The NRI (Buzby et al. 1988) was calculated as follows:

$$
\begin{aligned}
\mathrm{NRI}= & 1.519 \times \text { serum albumin }(\mathrm{g} / \mathrm{l})+41.7 \\
& \times(\text { current } / \text { usual body weight }) .
\end{aligned}
$$

Patients with NRI $>97.5$ were considered as non-malnourished, those with NRI 83.5-97.5 moderately malnourished, and those with a NRI $<83.5$ severely malnourished. Serum albumin levels were systematically measured on all blood samples taken between 21 and 30 May (week preceding the survey), and determined colorimetrically using bromocresol green dye binding with a Hitachi 917 analyser (Roche Diagnostics, Meylan, France). Usual body weight was recorded and current body weight measured during the week before the survey or during the survey by one of twelve registered dietitians who were part of every team. All subjects gave their informed consent and the study was performed according to the Helsinki Declaration of 1975 as revised in 1983, after oral and written information was given to all patients; their privacy was protected by the Commission Nationale Informatique et Libertés.

\section{Statistical analysis}

Values are expressed as means and standard deviations. Comparisons between populations were performed using Student's $t$ tests and $\chi^{2}$ tests. A search for factors related to NI was performed. Before implementation, variables considered for the analysis were carefully examined to determine those that were closely correlated in order to eliminate redundant ones. The following variables were studied: age, gender, immunodeficiency, NRI and its elements, surgical intervention, length of stay, type of stay, ward specialty, presence or absence of a vascular or urinary catheter and anti-infectious treatment. Logistic regressions were performed to analyse the impact of these variables on NI. Statistical significance was set at $P<0 \cdot 05$. Statistical analyses were performed using JMP software (SAS Institute Inc., Cary, NC, USA).

\section{Results}

We studied 1637 patients (801 men, 836 women; mean age 61.2 (SD 24.6) years). Serum albumin was measured in 1084 patients $(66.0 \%)$ and complete weight data was obtained in 911 patients $(57.5 \%)$ : actual body weight was measured in 1131 patients and usual body weight recorded in 1061 . NRI was calculated in 630 patients (38.5\%) (326 men, 304 women; mean age 61.4 (SD 19.8) years). Table 1 shows the characteristics of both the total population and the NRI population. The global prevalence of NI was $8.7 \%$; it was $8.1 \%$ in the NRI population $(P=0 \cdot 66)$. The main sites of infection are represented on Fig. 1. Forty-two of the seventy patients with urinary tract infections had asymptomatic bacteriuria (thirtysix had a urinary catheter in place). Among the twenty-eight with a symptomatic urinary infection, fifteen had a catheter in place. The urinary catheter had been placed on the day of the survey in thirty-three of the fifty-one patients with a catheter-associated urinary tract infection. The main micro-organisms involved in total infections are represented on Fig. 2. Bacteria most frequently encountered were Escherichia coli (n 29), Staphylococcus aureus (n 28), Enterococci ( $n$ 11), Pseudomonas aeruginosa (n 10) and Campylobacter ( $n$ 9).

According to the NRI classification, 203 patients $(32.2 \%)$ were not malnourished, 290 (46.0\%) were 
Table 1. Characteristics of all patients and patients in which the nutritional risk index was calculated ${ }^{\star}$

\begin{tabular}{|c|c|c|c|c|c|}
\hline & \multicolumn{2}{|c|}{$\begin{array}{l}\text { All patients } \\
(n 1637)\end{array}$} & \multicolumn{2}{|c|}{$\begin{array}{l}\text { NRI population } \\
\quad(n \text { 630) }\end{array}$} & \multirow{2}{*}{$\begin{array}{l}\text { Statistical significance } \\
\text { of difference: } P\end{array}$} \\
\hline & $n$ & $\%$ & $n$ & $\%$ & \\
\hline Age (years) $†$ & $61 \cdot 2$ & $24 \cdot 6$ & 61.4 & $19 \cdot 8$ & 0.88 \\
\hline Gender-ratio (male $(n)$ : female $(n))$ & \multicolumn{2}{|c|}{0.96} & \multicolumn{2}{|c|}{1.07} & 0.23 \\
\hline Length of stay in acute-care wards (d) $\dagger$ & 14 & 34 & 11 & 23 & 0.04 \\
\hline Ward specialty: & & & & & $<0.0001$ \\
\hline Medicine & 828 & $50 \cdot 6$ & 393 & $62 \cdot 4$ & \\
\hline Surgery & 379 & 23.2 & 153 & $24 \cdot 2$ & \\
\hline Geriatrics & 281 & $17 \cdot 1$ & 54 & $8 \cdot 6$ & \\
\hline Intensive care units & 77 & $4 \cdot 7$ & 17 & $2 \cdot 7$ & \\
\hline Other & 72 & 4.4 & 13 & $2 \cdot 1$ & \\
\hline Type of stay: & & & & & $<0.0001$ \\
\hline Acute-care & 1261 & $77 \cdot 0$ & 549 & $87 \cdot 1$ & \\
\hline Intermediate-care & 235 & 14.4 & 78 & $12 \cdot 4$ & \\
\hline Long-stay & 141 & 8.6 & 3 & 0.5 & \\
\hline Surgical intervention & 377 & 23.0 & 144 & $22 \cdot 8$ & 0.72 \\
\hline
\end{tabular}

${ }^{*}$ For details of selection of patients, see p. 106. † Mean values and standard deviations.

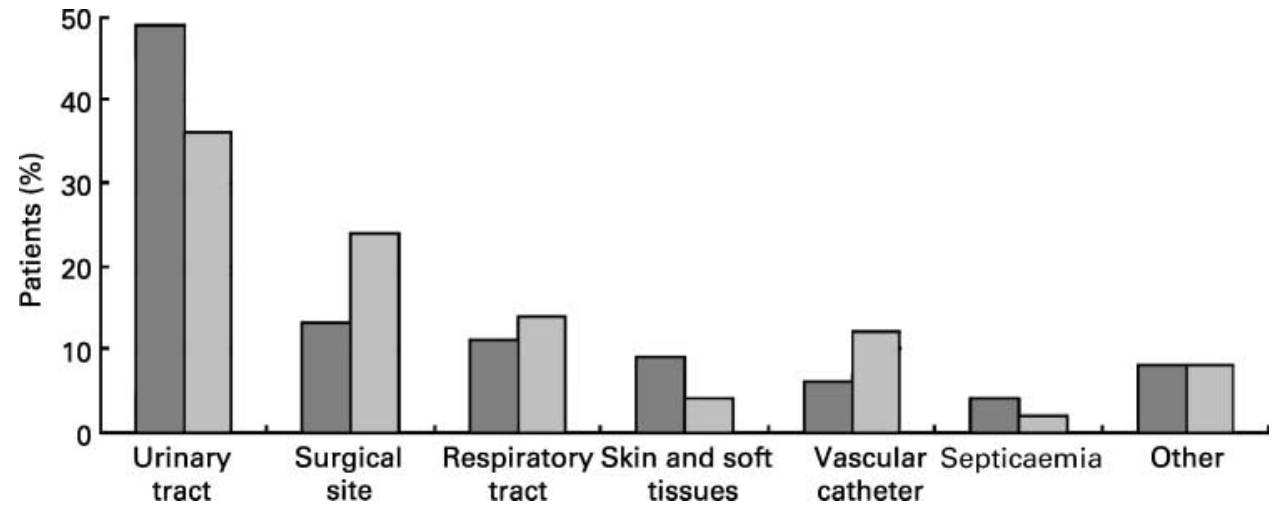

Fig. 1. Main nosocomial infection sites in all patients $(n$ 1637) and in patients in whom the nutritional risk index (NRI) was calculated $(n 630)$. - All patients; $\square$, NRI population. For details of patients and procedures, see Table 1 and p. 106. Mean values were significantly different from those of all patients: ${ }^{*} P=0.50$.

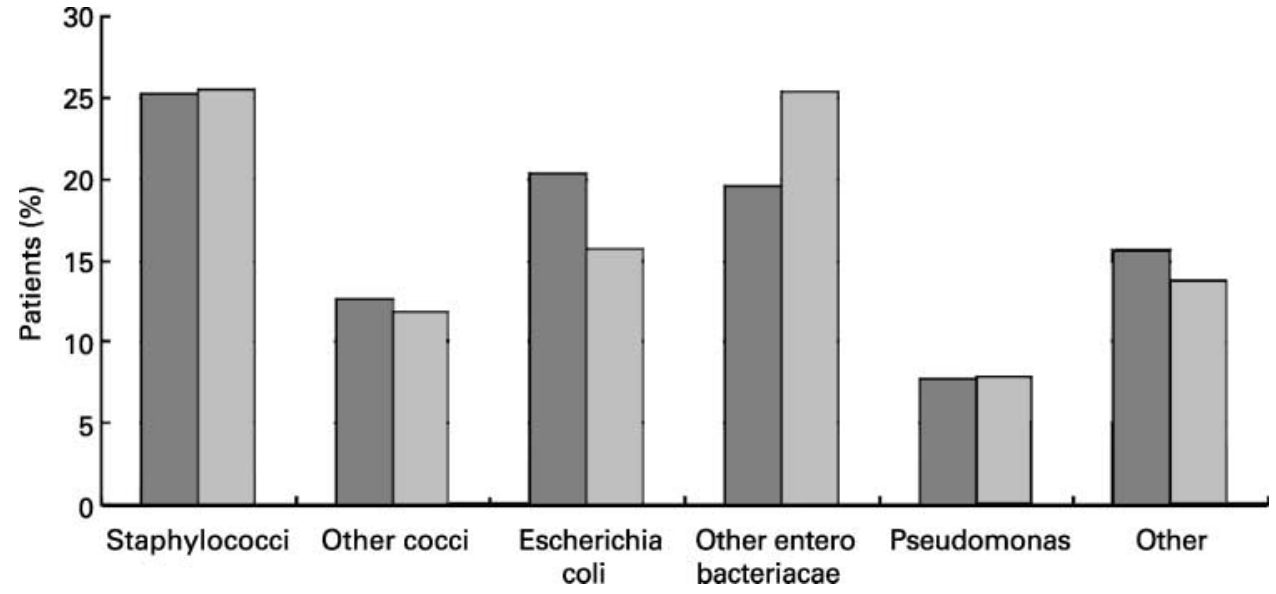

Fig. 2. Main bacteria responsible for nosocomial infections in all patients $(n 1637)$ and in patients in whom the nutritional risk index (NRI) was calculated $(n 630)$. $\quad$, All patients; - , NRI population. For details of patients and procedures, see Table 1 and p. 106. Mean values for NRI group were not significantly different from those of all patients: $P=0.99$.

moderately malnourished and $137(21.8 \%)$ were severely malnourished.

The prevalence of NI was $4.4 \%$ in non-malnourished patients, $7.6 \%$ in moderately malnourished patients and
$14.6 \%$ in severely malnourished patients $\left(\chi^{2}\right.$ test, $P=0.009)$. In univariate analysis, the following patientassociated variables were found to be associated with NI: serum albumin levels $\left(r^{2} 0 \cdot 04, P=0.04\right)$, age $\left(r^{2} 0.06\right.$, 
Table 2. Risk factors for nosocomial infection* $\dagger$

\begin{tabular}{|c|c|c|c|c|c|}
\hline \multicolumn{3}{|c|}{ Patient-related factors } & \multicolumn{3}{|c|}{ Procedure-related factors } \\
\hline Variable & Odds ratio & $95 \% \mathrm{Cl}$ & Variable & Odds ratio & $95 \% \mathrm{Cl}$ \\
\hline $\mathrm{NRI}$ & & & Type of stay & & \\
\hline$\geq 97.5$ & 1.00 & & Acute-care & 1.00 & \\
\hline $83.5-97.5$ & 1.46 & $1 \cdot 21,2 \cdot 11$ & Intermediate-care and long-stay & 5.73 & $5 \cdot 38,6 \cdot 08$ \\
\hline$<83.5$ & 4.98 & $4.60,6.40$ & & & \\
\hline Age & & & Length of stay & & \\
\hline$\leq 40$ years & 1.00 & & $\leq 7 \mathrm{~d}$ & 1.00 & \\
\hline$>40$ years & 1.97 & $1 \cdot 84,2 \cdot 10$ & $>7 d$ & $5 \cdot 07$ & $4 \cdot 87,5 \cdot 27$ \\
\hline Current weight & & & Surgical intervention & & \\
\hline$\geq 50 \mathrm{~kg}$ & 1.00 & & No & 1.00 & \\
\hline$<50 \mathrm{~kg}$ & $10 \cdot 40$ & $9 \cdot 50,11 \cdot 30$ & Yes & 2.90 & $2.51,3.29$ \\
\hline Plasma albumin & & & Urinary catheter & & \\
\hline$\geq 35 \mathrm{~g} / \mathrm{l}$ & 1.00 & & No & 1.00 & \\
\hline$<35 \mathrm{~g} / 1$ & 1.36 & $1.34,1.38$ & Yes & $9 \cdot 00$ & $8 \cdot 87,9 \cdot 13$ \\
\hline Immunodeficiency & & & Vascular catheter & & \\
\hline No & 1.00 & & No & 1.00 & \\
\hline Yes & 1.80 & $1.45,2.15$ & Yes & 2.08 & $2.07,2.09$ \\
\hline
\end{tabular}

$\mathrm{NRI}$, nutritional risk index.

* For details of patients and procedures, see Table 1 and p. 106

† Univariate analysis by multiple logistic regression.

$P=0 \cdot 05)$, actual weight $\left(r^{2} 0 \cdot 054, P=0 \cdot 02\right)$, immunodeficiency $\left(r^{2} 0 \cdot 14, P=0 \cdot 0007\right)$ and NRI $\left(r^{2} 0 \cdot 12, P=0 \cdot 01\right)$. The following procedure-associated variables were found to be associated with NI: length of hospital stay $\left(r^{2}\right.$ $0.034, P=0.06)$, type of stay $\left(r^{2} 0.065, P=0.04\right)$, surgical intervention $\left(r^{2} 0.12, P=0.001\right)$, presence of a vascular catheter $\left(r^{2} 0 \cdot 16, P=0 \cdot 0001\right)$, presence of a urinary catheter $\left(r^{2} 0 \cdot 39, P<0 \cdot 0001\right)$. Neither the type of ward (medical, surgical, geriatric, intensive care unit) nor the antibiotics received on the day of the survey influenced the risk of NI. Table 2 shows the odds ratios associated with each of these variables. In multivariate analysis, patient-associated variables significantly associated to the risk of NI included immunodeficiency $(P=0.002)$, age $(P=0.01)$ and NRI $(P=0.03)$; procedure-associated variables were surgical intervention $(P=0 \cdot 01)$, presence of a vascular catheter $(P=0.007)$ and presence of a urinary catheter $(P<0.0001)$, with odds ratios ranging from 2.08 $(95 \%$ CI $1.82,2.62)$ for vascular catheters to $10.80(95 \%$ CI $8.80,12.60)$ for association of the three. The retrospective analysis of the length of stay was 11.1 (SD 34.8) $d$ in non-malnourished patients, 17.5 (SD 37.4) d in moderately malnourished patients and 22.0 (SD 25.5) d in severely malnourished patients ( $\chi^{2}$ test, $\left.P=0.0034\right)$.

\section{Discussion}

The present prospective study shows a prevalence of NI of $8.7 \%$ in an urban university hospital (approximately 2000 beds), with a marked relationship to the nutritional status. Malnutrition, as assessed by the NRI, was independently associated with a higher prevalence of NI.

Surveillance of NI has been widely accepted as a primary step toward prevention of NI (Haley, 1995). The gold standard is a prospective, on-site, continuous, hospital-wide surveillance. However, these incidence surveys require extensive resources. Therefore, prevalence studies, which are easier to perform and less expensive, are often conducted to provide baseline information about the occurrence of NI and to help establish priorities for infection control. Most European countries, as well as the USA, Australia, Thailand and Mauritius, have organized prevalence studies (Gastmeier et al. 1998; Weinstein et al. 1999). An international prevalence study also has been conducted by the WHO (Mayon-White et al. 1988).

Many variables have been used to describe the nutritional status of hospitalized patients, including assessments of oral intake, body weight and loss of body weight, anthropometric data, hepatic secretory proteins and body composition analysis. However, even if these epidemiologically useful indicators correlate with morbidity and mortality (Mullen et al. 1979), no single measurement is of value in individual patients (Schneider \& Hébuterne, 2000). Albumin is an integrative biological marker, which is associated with both body composition and the acute-phase response in patients. For this reason it is a very good cumulative variable of individual disease stage and activity, but usually not nutritional status (Klein, 1990), as it may be found in various other conditions (including hepatic and renal failure) and more generally in any situation when a systemic inflammatory response is involved, following injury, infection or inflammation (Rady et al. 1997; Llop et al. 2001; McMillan et al. 2001). Many studies have shown that albumin has strong prognostic power in numerous disease states, which makes it an ideal tool for stratifying patient groups. For example, hypoalbuminaemia alone has proved to be a valid negative prognostic factor, being associated with increased occurrences of NI, length of stay and mortality (Herrmann et al. 1992; McClave et al. 1992; Rady et al. 1997; Llop et al. 2001). Consequently, several clinical scores have been developed, including the NRI (Buzby et al. 1988). The NRI takes into account semi-starvation and the systemic inflammatory response, both relevant causes of hospital malnutrition. It is simple to calculate, inexpensive and reproducible. Furthermore, two studies 
suggest that NRI is more accurate than the subjective global assessment in determining which patients are most at risk of contracting an infection (Naber et al. 1997b) and which patients will benefit the most from nutritional support (Anonymous, 1991).

The overall prevalence of NI in our present study is comparable with that found in other point-prevalence studies in teaching hospitals or medical centres with more than 500 beds (4.4-14.8\%; Mayon-White et al. 1988; Weinstein et al. 1999; Anonymous, 2000). The particular strength of the present study is the in-depth analysis of possible intrinsic and extrinsic risk factors for NI.

Urinary tract, surgical sites and respiratory infections accounted for $>70 \%$ of all infections, both in all patients and in the NRI population. The bacteria causing the infections, mainly staphylocci and gram-negative bacilli, were also comparable between the two populations. The high prevalence of urinary tract infections and the high-risk of NI in patients with a urinary catheter are well known (Weinstein et al. 1999). Moreover, the systematic screening for urinary tract infections in patients who had had a urinary catheter in place on the day of the survey, or in any of the $7 \mathrm{~d}$ before the survey, certainly enhanced the recognition (and therefore the prevalence) of urinary tract infections. Despite the very high odds ratio reported for urinary catheters, the other correlations found were significant, which is why we did not exclude urinary tract infections (which are one of the most common forms of NI) from the statistical analysis. However, this high odds ratio led us to separate patient-related variables from procedure-related variables in the multivariate analysis, as otherwise the former would have lost statistical significance.

There was no difference in age and gender between the population in which NRI was measured and the total hospital population. The prevalence and characteristics of NI were also similar in both populations, allowing us to apply the NRI group findings to the general population. However, NRI could only be calculated in three out of the 141 long-stay patients. There were several reasons: (1) lack of albumin values, since no blood sample was taken especially for the purpose of the present study (as this population with a long-term stay rarely has blood drawn, this explains the low number of albumin values obtained); (2) lack of knowledge of usual weight, as recalling usual weight can be difficult in demented or severely ill patients, who represent an important part of this population; (3) lack of current weight, since measuring weight on scales is impossible in bedridden patients without special devices that were absent from these facilities. We believe that the difference in ward specialty between the NRI population (more medical wards, less geriatrics) and the total population did not introduce an important bias, as accommodation is comparable in both types of wards, and the staff follow the same procedures.

Malnutrition was present in $68 \%$ of the patients: $46 \%$ were moderately malnourished and $22 \%$ were severely malnourished. Protein-energy malnutrition, or the possibility of developing it, has been reported to occur in 37-82\% of patients in urban teaching hospitals (Tucker \& Miguel, 1996), so our present results fall in the upper range. This wide range may be explained by differences in the criteria used in assessing malnutrition and in the case mix of patients in the various hospital populations (Naber et al. $1997 a$ ). The prevalence of severe malnutrition in comparable studies ranges from 6\% (Naber et al. 1997b) to $23.1 \%$ (Kyle et al. 2002) using the subjective global assessment, and from $8.4 \%$ (Anonymous, 1991) to $13 \%$ (Naber et al. 1997b) using the NRI. However, only one study is similar to ours in that non-selected patients admitted to every ward of a university hospital (Geneva, Switzerland) were enrolled; in that study, a prevalence of severe malnutrition of $23.1 \%$ was reported (Kyle et al. 2002). Our present study, like others (Edington et al. 2000; Thomas et al. 2002), found an increased length of stay in malnourished patients.

Analysis of factors associated with NI revealed several independent variables. Extrinsic factors associated with NI included surgery and the presence of vascular and/or urinary catheters. Association between these factors and NI has been shown (Setia et al. 1985; Trilla et al. 1991). Intrinsic factors included age and immunodeficiency (Setia et al. 1985; Trilla et al. 1991): immunodeficiency had the strongest statistical relationship with NI among patient-related variables, probably because, as with albumin, it is to a large extent a marker of disease stage and activity. Intrinsic factors also included malnutrition. A recent study of 4000 patients hospitalized in Brazil found the variables age $>60$ years, cancer, infection and length of hospital stay $>15 \mathrm{~d}$ as independent risk factors for malnutrition (Waitzberg et al. 2001). However, the analysis makes it difficult to ascertain if infection favours malnutrition or if it is malnutrition that induces infection. The diagnoses and the severity of illness were not recorded in our patients, but strong evidence from the literature allows us to think that they probably did not affect the statistical link between malnutrition and the risk of NI (Sullivan \& Walls, 1995), especially as our statistical model included diseases such as AIDS and metastatic cancer, and immuno-suppressive treatment.

As it both treats semi-starvation and provides metabolic support to patients who are experiencing a significant systemic inflammatory response, artificial nutrition reduces the complications (especially infectious) in severely malnourished patients (Anonymous, 1991); this is why screening for malnutrition is aimed at providing nutritional support in order to prevent co-morbidities. A study has shown that for each $2 \mathrm{~d}$ of earlier nutritional support there was a decline of $1 \mathrm{~d}$ in length of stay for the average patient (Tucker \& Miguel, 1996). Unfortunately, references to nutritional status are present in less than half of the patients' hospital records (McWhirter \& Pennington, 1994; Waitzberg et al. 2001) and untrained physicians fail to detect malnutrition (Roubenoff et al. 1987). As a result, nutritional status declines during the course of hospitalization (Weinsier et al. 1979; Gariballa, 2001). Health professionals need to be more aware of malnutrition and its consequences, and the presence of nutritional support teams will certainly help to increase awareness among professionals, with the ultimate aim of reducing the prevalence and consequences of hospital malnutrition (Hassell et al. 1994). The strong statistical relationship between 
malnutrition and NI leads us to hypothesize that addressing hospital malnutrition will lead to a decrease in the number of NI, as implementation of malnutrition screening and treatment at hospital scale has been showed to reduce length of stay, cost of care and severe disease complications (Brugler et al. 1999). Therefore, this calls for intervention studies. Finally, knowing the consequences of malnutrition and not looking for it may have medicolegal consequences.

In conclusion, NI are one of the many consequences of malnutrition in a hospital setting. Early screening for malnutrition may therefore be helpful to reduce the high prevalence of NI.

\section{Acknowledgements}

This study was supported by the Centre Hospitalier Universitaire de Nice. The authors wish to thank all survey investigators, Mireille Negrel, RD and Simone Stalins, RD and all the investigating dietitians; Patrick Rampal, MD, who developed Clinical Nutrition in the Nice University Hospital; Jean-Jacques Romatet, Director of the Nice University Hospital and Dominique Grimaud, MD, former Head of the Medical Committee in the same hospital, who provided us with the human resources to conduct this study; Robert M. Russell, MD, for his precious advice in writing this manuscript.

\section{References}

Anonymous (1991) Perioperative total parenteral nutrition in surgical patients. The Veterans Affairs Total Parenteral Nutrition Cooperative Study Group. N Engl J Med 325, 525-532.

Anonymous (1992) Anonymous Public health focus: surveillance, prevention, and control of nosocomial infections. MMWR Morb Mortal Wkly Rep 41, 783-787.

Anonymous (2000) Prevalence of nosocomial infections in France: results of the nationwide survey in 1996. The French Prevalence Survey Study Group. J Hosp Infect 46, 186-193.

Anker SD, Ponikowski P, Varney S, Chua TP, Clark AL, WebbPeploe KM, Harrington D, Kox WJ, Poole-Wilson PA \& Coats AJ (1997) Wasting as independent risk factor for mortality in chronic heart failure. Lancet 349, 1050-1053.

Brugler L, DiPrinzio MJ \& Bernstein L (1999) The five-year evolution of a malnutrition treatment program in a community hospital. Jt Comm J Qual Improv 25, 191-206.

Buzby GP, Knox LS, Crosby LO, Eisenberg JM, Haakenson CM, McNeal GE, Page CP, Peterson OL, Reinhardt GF \& Williford WO (1988) Study protocol: a randomized clinical trial of total parenteral nutrition in malnourished surgical patients. Am $J$ Clin Nutr 47, 366-381.

Edington J, Boorman J, Durrant ER, Perkins A, Giffin CV, James R, Thomson JM, Oldroyd JC, Smith JC, Torrance AD, et al (2000) Prevalence of malnutrition on admission to four hospitals in England. The Malnutrition Prevalence Group. Clin Nutr 19, 191-195.

Galanos AN, Pieper CF, Kussin PS, Winchell MT, Fulkerson WJ, Harrell FE Jr, Teno JM, Layde P, Connors AF Jr, Phillips RS, et al. (1997) Relationship of body mass index to subsequent mortality among seriously ill hospitalized patients. SUPPORT Investigators. The Study to Understand Prognoses and Preferences for Outcome and Risks of Treatments. Crit Care Med 25, 1962-1968.
Garcia-Martin M, Lardelli-Claret P, Jimenez-Moleon JJ, BuenoCavanillas A, Luna-del-Castillo JD \& Galvez-Vargas R (2001) Proportion of hospital deaths potentially attributable to nosocomial infection. Infect Control Hosp Epidemiol 22, $708-714$.

Gariballa SE (2001) Malnutrition in hospitalized elderly patients: when does it matter? Clin Nutr 20, 487-491.

Garner JS, Jarvis WR, Emori TG, Horan TC \& Hughes JM (1988) CDC definitions for nosocomial infections, 1988. Am J Infect Control 16, 128-140.

Gastmeier P, Kampf G, Wischnewski N, Schumacher M, Daschner F \& Ruden H (1998) Importance of the surveillance method: national prevalence studies on nosocomial infections and the limits of comparison. Infect Control Hosp Epidemiol 19, 661-667.

Haley RW (1995) The scientific basis for using surveillance and risk factor data to reduce nosocomial infection rates. J Hosp Infect 30, 3-14.

Hassell JT, Games AD, Shaffer B \& Harkins LE (1994) Nutrition support team management of enterally fed patients in a community hospital is cost-beneficial. J Am Diet Assoc 94, 993-998.

Herrmann FR, Safran C, Levkoff SE \& Minaker KL (1992) Serum albumin level on admission as a predictor of death, length of stay, and readmission. Arch Intern Med 152, $125-130$.

Horan TC, Gaynes RP, Martone WJ, Jarvis WR \& Emori TG (1992) CDC definitions of nosocomial surgical site infections, 1992: a modification of CDC definitions of surgical wound infections. Am J Infect Control 20, 271-274.

Jarvis WR (1996) Selected aspects of the socioeconomic impact of nosocomial infections: morbidity, mortality, cost, and prevention. Infect Control Hosp Epidemiol 17, 552-557.

Kirkland KB, Briggs JP, Trivette SL, Wilkinson WE \& Sexton DJ (1999) The impact of surgical-site infections in the 1990s: attributable mortality, excess length of hospitalization, and extra costs. Infect Control Hosp Epidemiol 20, 725-730.

Klein S (1990) The myth of serum albumin as a measure of nutritional status. Gastroenterology 99, 1845-1846.

Kyle UG, Unger P, Mensi N, Genton L \& Pichard C (2002) Nutrition status in patients younger and older than $60 \mathrm{y}$ at hospital admission: a controlled population study in 995 subjects. Nutrition 18, 463-469.

Llop JM, Munoz C, Badia MB, Virgili N, Tubau M, Ramon JM, Pita A \& Jodar JR (2001) Serum albumin as indicator of clinical evolution in patients on parenteral nutrition. Multivariate study. Clin Nutr 20, 77-81.

McClave SA, Mitoraj TE, Thielmeier KA \& Greenburg RA (1992) Differentiating subtypes (hypoalbuminemic vs marasmic) of protein-calorie malnutrition: incidence and clinical significance in a university hospital setting. J Parenter Enter Nutr 16, 337-342.

McMillan DC, Watson WS, O'Gorman P, Preston T, Scott HR \& McArdle CS (2001) Albumin concentrations are primarily determined by the body cell mass and the systemic inflammatory response in cancer patients with weight loss. Nutr Cancer 39, 210-213.

McWhirter JP \& Pennington CR (1994) Incidence and recognition of malnutrition in hospital. Br Med J 308, 945-948.

Mayon-White RT, Ducel G, Kereselidze T \& Tikomirov E (1988) An international survey of the prevalence of hospital-acquired infection. $J$ Hosp Infect 11, 43-48.

Mullen JL, Gertner MH, Buzby GP, Goodhart GL \& Rosato EF (1979) Implications of malnutrition in the surgical patient. Arch Surg 114, 121-125.

Naber TH, de Bree A, Schermer TR, Bakkeren J, Bar B, de Wild G \& Katan MB (1997a) Specificity of indexes of malnutrition 
when applied to apparently healthy people: the effect of age Am J Clin Nutr 65, 1721-1725.

Naber TH, Schermer T, de Bree A, Nusteling K, Eggink L, Kruimel JW, Bakkeren J, van Heereveld H \& Katan MB (1997b) Prevalence of malnutrition in nonsurgical hospitalized patients and its association with disease complications. Am J Clin Nutr 66, 1232-1239.

Rady MY, Ryan T \& Starr NJ (1997) Clinical characteristics of preoperative hypoalbuminemia predict outcome of cardiovascular surgery. J Parenter Enter Nutr 21, 81-90.

Robinson G, Goldstein M \& Levine GM (1987) Impact of nutritional status on DRG length of stay. J Parenter Enter Nutr 11, $49-51$.

Roubenoff R, Roubenoff RA, Preto J \& Balke CW (1987) Malnutrition among hospitalized patients. A problem of physician awareness. Arch Intern Med 147, 1462-1465.

Schneider SM \& Hébuterne X (2000) Use of nutritional scores to predict clinical outcomes in chronic diseases. Nutr Rev 58, $31-38$.

Scrimshaw NS \& SanGiovanni JP (1997) Synergism of nutrition, infection, and immunity: an overview. Am J Clin Nutr 66 464S-477S.

Setia U, Serventi I \& Lorenz P (1985) Nosocomial infections among patients in a long-term care facility: spectrum, prevalence, and risk factors. Am J Infect Control 13, 57-62.

Sullivan DH \& Walls RC (1995) The risk of life-threatening complications in a select population of geriatric patients: the impact of nutritional status. J Am Coll Nutr 14, 29-36.

Thomas DR, Zdrowski CD, Wilson MM, Conright KC, Lewis C,
Tariq S \& Morley JE (2002) Malnutrition in subacute care. Am J Clin Nutr 75, 308-313.

Trilla A, Gatell JM, Mensa J, Latorre X, Almela M, Soriano E, Jimenez de Anta MT \& Garcia San Miguel J (1991) Risk factors for nosocomial bacteremia in a large Spanish teaching hospital: a case-control study. Infect Control Hosp Epidemiol 12, 150-156.

Tucker HN \& Miguel SG (1996) Cost containment through nutrition intervention. Nutr Rev 54, 111-121.

Waitzberg DL, Caiaffa WT \& Correia MI (2001) Hospital malnutrition: the Brazilian national survey (IBRANUTRI): a study of 4000 patients. Nutrition 17, 573-580.

Weinsier RL, Hunker EM, Krumdieck CL \& Butterworth CE Jr (1979) Hospital malnutrition. A prospective evaluation of general medical patients during the course of hospitalization. Am J Clin Nutr 32, 418-426.

Weinstein JW, Mazon D, Pantelick E, Reagan-Cirincione P, Dembry LM \& Hierholzer WJ Jr (1999) A decade of prevalence surveys in a tertiary-care center: trends in nosocomial infection rates, device utilization, and patient acuity. Infect Control Hosp Epidemiol 20, 543-548.

Wenzel RP (1985) Nosocomial infections, diagnosis-related groups, and study on the efficacy of nosocomial infection control. Economic implications for hospitals under the prospective payment system. Am J Med 78, 3-7.

Worming AM (1994) Stratégies de réduction des infections nosocomiales. Un modèle pour le développement de la qualité (Strategies for reducing nosocomial infections. A model for developing quality). In Etudes de Politique de Santé (Reviews of Healthcare Systems), pp. 9-25. Paris, France: OCDE (OECD). 